\title{
Attention deficit hyperactivity disorder and drug addiction rehabilitation patients
}

\author{
Transtorno de Déficit de Atenção e Hiperatividade e pacientes em reabilitação de drogadição

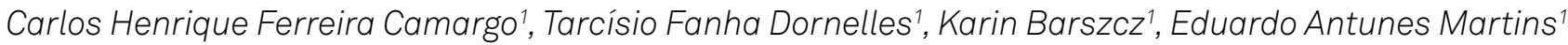

\begin{abstract}
Objective: Attention deficit hyperactivity disorder (ADHD) is characterized by a persistent pattern of inattention or hyperactivity. This study aimed to investigate the relationship between ADHD and drug dependence. Methods: The presence and severity of ADHD and substance use were evaluated through questionnaires in 80 adult patients in therapeutic communities. Results: No difference in drug use or dependence prevalence between ADHD and non-ADHD patients was found. However, ADHD patients had lower ages on admission ( $p=0.004$ ) and at first contact with cocaine $(p=0.033)$. In ADHD patients, there was a negative correlation between the age at first use of cannabis and the subsequent severity of cannabis use $(p=0.017)$ and cocaine use $(p=0.033)$. Conclusions: Though there was no difference in prevalence of drug use among groups, results show that ADHD in patients in therapeutic communities may cause different addiction patterns, such as earlier use of cocaine and admission, and a more severe use of cocaine correlated to earlier contact with cannabis.
\end{abstract}

Keywords: attention deficit disorder with hyperactivity; substance-related disorders; cocaine.

\section{RESUMO}

Objetivo: O Transtorno de Déficit de Atenção e Hiperatividade (TDAH) é caracterizado por um padrão de desatenção ou hiperatividade. Este estudo investigou relações entre TDAH e dependência de substância. Métodos: Prevalência e gravidade de TDAH e de uso de substância foram avaliadas em oitenta pacientes adultos de comunidades terapêuticas. Resultados: Não houve diferença de prevalência de uso e dependência de substância entre pacientes com e sem TDAH. Pacientes TDAH tiveram menor idade de admissão $(p=0,004)$ e de primeiro contato com cocaína $(p=0,033)$. Em pacientes TDAH, houve correlação negativa entre idade de primeiro uso de cannabis e gravidade do uso de cannabis $(p=0,017)$ e cocaína ( $p=0,033)$. Conclusões: Mesmo sem haver diferença na prevalência de uso de substância entre os grupos, conclui-se que o TDAH nos pacientes de comunidade terapêutica pode ter induzido padrão diferente da drogadição, como idade precoce de admissão e de uso de cocaína, e uso mais grave de cocaína relacionado a contato precoce com cannabis.

Palavras-chave: transtorno do deficit de atenção com hiperatividade; transtornos relacionados ao uso de substâncias; cocaína.

Attention deficit hyperactivity disorder (ADHD) manifests as a behavioral pattern that leads to significant social, educational and occupational impairment. The main characteristics of the disorder are inattention, hyperactivity and impulsivity ${ }^{1}$. The diagnosis of ADHD is clinical and is based on a persistent, early-onset clinical picture that manifests in different settings and leads to functional loss'2.

A failure in behavioral inhibition is believed to lead to the predominant symptoms of ADHD: hyperactivity, inattention, distraction and impulsivity ${ }^{3}$.

The changes in the catecholaminergic pathways are believed also to involve the nucleus accumbens, with impairment of selective attention and the reward system ${ }^{4}$, which may be associated with a greater risk of substance use and dependence ${ }^{5}$. The risk of dependence on alcohol or other substances is significantly higher in adolescents with attention-related difficulties than in healthy adolescents ${ }^{6}$. Hence, because of the impulsivity and inattention associated with the condition, ADHD may be a risk factor for substance use disorder ${ }^{5}$, a set of cognitive, behavioral and physiological symptoms that cause occupational impairment as a result of the use of a particular substance. Substance dependence is a clinical condition at the more severe end of the substance use disorder spectrum. Even when occupationally incapacitated, dependent individuals continue to use substances. Drugs described as potentially causing dependence include nicotine, alcohol, cannabis, and cocaine and its derivatives ${ }^{1}$.

The aims of this study were to identify the presence of ADHD and its subtypes in patients in rehabilitation for chemical

${ }^{1}$ Universidade Estadual de Ponta Grossa, Hospital Universitário, Departamento de Medicina, Serviço de Neurologia, Ponta Grossa PR, Brasil.

Correspondence: Carlos Henrique Ferreira Camargo; Hospital Regional Universitário dos Campos Gerais - UEPG; Alameda Nabuco de Araújo, 601; 84031-510 Ponta Grossa PR, Brasil; E-mail: chcamargo@uol.com.br

Conflict of interest: There is no conflict of interest to declare.

Received 07 February 2016; Received in final form 08 September 2016; Accepted 13 September 2016. 
dependence and compare the patterns of drug-addiction, with regard to frequency and severity of substance use and dependence, age on admission and age of first use, between ADHD and non-ADHD patients. In addition, the study aimed to investigate the correlation of ages at first use of substance, age on admission to the therapeutic community and severity of use of substance, in order to explore the relationship between ADHD symptom frequency and the pattern of substance use.

\section{METHODS}

Eighty consecutive patients (53 males and 27 females) admitted between July 2013 and December 2014 to two rehabilitation centers for chemical dependents (Rosa Mística and Padre Wilton therapeutic communities) were selected. Inclusion criteria were: having a history of drug use; being in a rehabilitation center; and being aged 18 or over. Exclusion criteria were: refusing to sign the voluntary informed-consent form and cognitive and behavioral incapacitation.

The study was approved by the human research ethics committee at Ponta Grossa State University under reference no. 261.273 .

\section{Definitions and criteria}

The diagnostic criteria in the Diagnostic and Statistical Manual of Mental Disorders (DSM-IV-TR) ${ }^{7}$ were used to identify the presence of $\mathrm{ADHD}$ and to classify it into subtypes. Individuals were considered to be substance users if they reported having had at least one contact with the substance during their lives.

The Adult ADHD Self-report Scale symptom checklist (ASRS-18) was applied to qualify and quantify $\mathrm{ADHD}^{8,9}$, mainly by accessing the frequency of $\mathrm{ADHD}$ symptoms. In the evaluation, the patients were questioned about symptoms present during primary school attendance, and therefore without influence of possible negative outcomes of drug use disorder that could simulate symptoms of inattention and hyperactivity.

The Alcohol, Smoking and Substance Involvement Screening Test (ASSIST) was used to identify, qualify and quantify substance use and dependence ${ }^{10,11}$. The test was applied to investigate alcohol, tobacco and cannabis use, as well as the use of cocaine and its derivatives. The total score in this test was given by the sum of the values assigned to the ASSIST questions related to occupational impairment caused by substance use or dependence. Substance use was considered to be present if an individual had had contact with substances at least once in their life, and dependence was defined as corresponding to a score of more than 16/20.

\section{Assessment of ADHD symptoms, substance use and dependence}

The voluntary informed-consent form was explained to patients. After it had been signed, the ASRS-18 and ASSIST questionnaires were applied, in that order.
During the first part of the ASSIST questionnaire, patients were asked what age they were when they first used the substances they reported having had contact with and when they were admitted to the rehabilitation center.

\section{Classifications and scores}

Each answer to the questionnaires had a specific value, and they were summed for a final score. This score was used to classify the patient into the referred categories, such as ADHD or non-ADHD, for instance, following the instructions of the questionnaire. The score was also used as an evaluation of frequency of symptoms of ADHD or severity of drug use or dependence. Therefore, patients were classified as ADHD or non-ADHD, as well for their subtypes; and as a user, dependent or non-user of each studied substance. They also received a score of ADHD symptom frequency and drug use or dependence severity. The age at first use of substance and age on admission were also used for comparison.

According to the classification received, patients were divided into groups. Then, the statistic comparison of these groups was carried out. In addition, scores and ages were also used for correlations.

\section{Statistical analysis}

The two-tailed Fisher's exact test was used to compare the presence of use and dependence on substance in ADHD and non-ADHD groups, as well to compare the number of cocaine dependent individuals and the number of individuals dependent on other drugs.

The Student $t$ test was used to compare the severity of drug use between ADHD and non-ADHD users, as well as for the ages at first use of the substance and age on admission. The effect size was analyzed using Cohen's d coefficient for continuous variables ( 0.2 - weak effect; 0.5 - moderate effect; and 0.8 - strong effect).

The degree of correlation between the variables was calculated using Pearson's correlation, to compare the score in ARSR-18 and the age at first use of substance, and to correlate age at first use of substance and age on admission and age at first use of substance and prior use severity. P values of less than 0.05 were considered statistically significant. SPSS 21, GraphPad and Microsoft Office Excel ${ }^{\circ}$ were used for the analysis.

\section{RESULTS}

Of the 80 patients, 49 (61.25\%) were classified as having clinical findings suggestive of ADHD. Seventy-two patients had dependence on other drugs as opposed to only alcohol and were considered polydrug users, but there was no statistical difference between ADHD and non-ADHD populations $(p=0.0501)$. The drugs with the greatest and smallest number 
of users were alcohol and cocaine, respectively. This was true for the population with $\mathrm{ADHD}$ and the population without ADHD (Table 1), and a similar result was observed for populations with different subtypes of ADHD (Table 2). Also, no difference between the two groups (predominantly attention deficit or predominantly hyperactivity/impulsivity) was found in relation to number of users and type of drugs (Table 2). The drugs with the greatest and smallest number of dependents were cocaine and cannabis, respectively, a pattern that was repeated in all the populations. Cocaine had the highest percentage of dependent users (Table 1). Of the patients who had had at least occasional contact with cocaine, $77.78 \%$ developed dependence, while for the other drugs considered together, the corresponding figure was $40.5 \%$ ( $p<0.0001$ ). There was no statistically significant difference in the frequency of substance use and dependence between men and women.

The mean age of the patients admitted to the therapeutic communities was $32.63 \pm 9.718$ years. The patients had diverse social origins and educational or economic levels.
The difference of economic settings of the patients were reflected in their ability to acquire the substance and their possible enrollment in criminal activities. Some patients were in rehabilitation under judicial sentence. A previous diagnosis of ADHD or treatment was not referred to by the patients. Therefore, this study is not able to assess a different drug addiction prognosis in the treatment of $\mathrm{ADHD}$ patients.

Age at first use of cocaine and its derivatives was lower among the ADHD population ( $p=0.033$, Cohen's $d=0.64$ ), as was age on admission to rehabilitation ( $p=0.004$, Cohen's $\mathrm{d}=0.67$ ) (Table 3 ). In the $\mathrm{ADHD}$ population evaluation, there was an inverse correlation between age at first use of cannabis and cannabis use score $(r=-0.350, p=0.017)$ and cocaine use score $(r=-0.318, p=0.035)$. These results were not observed in the group without ADHD. The age at their first contact with alcohol was lower for men than for women ( $p=0.008$; Cohen's $\mathrm{d}=0.89$ ). No differences were found in the mean age on admission to rehabilitation and mean age at first substance use between ADHD subtypes (Table 4).

Table 1. Substance use and dependence among patients with and without ADHD.

\begin{tabular}{|c|c|c|c|c|c|c|}
\hline \multirow{2}{*}{ Variable } & \multicolumn{3}{|c|}{ Substance use } & \multicolumn{3}{|c|}{ Substance dependence } \\
\hline & ADHD & non-ADHD & $p$ & ADHD & non-ADHD & $p$ \\
\hline Tobacco & 45 & 28 & 1 & 15 & 12 & 0.4766 \\
\hline Alcohol & 48 & 31 & 1 & 27 & 15 & 0.3913 \\
\hline Cannabis & 44 & 24 & 0.1980 & 10 & 5 & 0.6470 \\
\hline Cocaine & 40 & 23 & 0.5757 & 32 & 17 & 0.3592 \\
\hline
\end{tabular}

ADHD: attention deficit and hyperactivity disorder.

Table 2. Substance use and dependence by ADHD subtype.

\begin{tabular}{|c|c|c|c|c|c|c|}
\hline \multirow{2}{*}{ Variable } & \multicolumn{3}{|c|}{ Substance use } & \multicolumn{3}{|c|}{ Substance dependence } \\
\hline & $\mathrm{ADHD}-\mathrm{HI}^{*}$ & ADHD $-I N^{* *}$ & $\mathrm{p}$ & $\mathrm{ADHD}-\mathrm{HI}^{*}$ & ADHD - IN** & $p$ \\
\hline Tobacco & 22 & 21 & 1 & 8 & 6 & 0.7516 \\
\hline Alcohol & 24 & 23 & 1 & 13 & 12 & 1 \\
\hline Cannabis & 21 & 21 & 1 & 5 & 5 & 1 \\
\hline Cocaine & 21 & 17 & 0.4513 & 15 & 16 & 0.7601 \\
\hline
\end{tabular}

ADHD: attention deficit and hyperactivity disorder; *characterized predominantly by hyperactivity and impulsivity; ** characterized predominantly by inattention.

Table 3. Age on admission and at first use for individuals with and without ADHD.

\begin{tabular}{|c|c|c|c|c|}
\hline Variable & Overall & $\operatorname{ADHD}(n)$ & non-ADHD (n) & p* \\
\hline Age on admission & $32.63 \pm 9.718(80)$ & $30.16 \pm 8.493(49)$ & $36.52 \pm 10.379(31)$ & 0.004 \\
\hline \multicolumn{5}{|l|}{ Age at first use } \\
\hline Tobacco & $14.11 \pm 3.458(74)$ & $13.57 \pm 3.153(46)$ & $15 \pm 3.801(28)$ & 0.083 \\
\hline Alcohol & $14.76 \pm 4.152(79)$ & $14.25 \pm 3.111(48)$ & $15.55 \pm 5.347(31)$ & 0.176 \\
\hline Cannabis & $16.06 \pm 3.686(69)$ & $15.55 \pm 2.953(44)$ & $16.96 \pm 4.641(25)$ & 0.178 \\
\hline Cocaine & $18.78 \pm 6.227(63)$ & $17.2 \pm 3.228(40)$ & $21.52 \pm 8.856(23)$ & 0.033 \\
\hline
\end{tabular}

ADHD: attention deficit and hyperactivity disorder; * Patients with and without ADHD.

Table 4. Age on admission and at first use by ADHD subtype.

\begin{tabular}{lccc}
\hline Variable & ADHD $-H *(n)$ & ADHD $-I N * *(n)$ & $p$ \\
\hline Age on admission & $31.25 \pm 8.36(24)$ & $29.26 \pm 8.81(23)$ & 0.431 \\
Age at first use & & & \\
Tobacco & $14.46 \pm 2.58(22)$ & $12.82 \pm 3.56(21)$ & 0.88 \\
Alcohol & $14.71 \pm 3.56(24)$ & $14.32 \pm 1.86(23)$ & 0.64 \\
Cannabis & $15.76 \pm 3.77(21)$ & $15.43 \pm 2.09(21)$ & 0.725 \\
Cocaine & $17.52 \pm 3.24(21)$ & $16.94 \pm 3.33(17)$ & 0.586 \\
\hline
\end{tabular}

ADHD: attention deficit and hyperactivity disorder; ${ }^{*}$ characterized predominantly by hyperactivity and impulsivity; ${ }^{\star *}$ characterized predominantly by inattention. 
There was a correlation between a higher score in the assessment of DSM-IV-TR criteria A (ASRS-18) - ADHD symptoms frequency and age of first use for all the substances studied [tobacco $(r=-0.254 ; \mathrm{p}=0.029)$, alcohol $(\mathrm{r}=-0.242 ; \mathrm{p}=0.032)$, cannabis $(\mathrm{r}=-0.337 ; \mathrm{p}=0.001)$ and cocaine $(r=-0.432 ; p<0.001)]$ and between frequency of ADHD symptoms and age on admission $(r=-0.370 ; p=0.001)$.

\section{DISCUSSION}

Of the 80 patients in rehabilitation, 49 (61.25\%) had clinical findings compatible with a diagnosis of $\mathrm{ADHD}$, a value significantly above the estimated global prevalence of $5.3 \%{ }^{12}$. This is compatible with the results reported by Ballon et al. ${ }^{13}$, who assessed 77 patients and found a higher prevalence of $\mathrm{ADHD}$ in cocaine dependent individuals than in controls.

As expected, because all the patients were in rehabilitation for chemical dependence, there was no statistically significant difference in the number of patients who had had some type of contact with substances and the number who developed severe substance use disorder, i.e., dependence, as a result of this contact. There was also no difference in occasional substance use and dependence (substance use disorder) between the different subtypes of ADHD, nor in the ages at first use of substance or age on admission. This finding is different from that reported by De Alwis et al. ${ }^{14}$, who found in a study of 33,588 patients from the population at large that the impulsive subtype of ADHD individuals had a greater tendency to use substances and develop dependence.

No statistically significant correlation between a higher score in ASRS-18 and severity of substance use disorder assessed by the application of ASSIST was observed for any of the substances individually. This may indicate that a patient with more frequent symptoms of ADHD does not necessarily progress to more frequent or harmful and incapacitating substance use, or that the ASRS-18 or ASSIST results may not be suitable to set this correlation. In contrast to our findings, Upadhyaya et al. ${ }^{15}$ found a positive correlation between the number of symptoms of ADHD and severity of tobacco, alcohol and cannabis use in a sample of 334 university students.

Despite this apparent lack of an association between $\mathrm{ADHD}$ and severity of substance use in the present study, there was a significant difference in age at first use of cocaine between groups with and without ADHD. Corroborating this finding, Dunne et al. ${ }^{16}$ found a lower age at first use of cocaine among patients with ADHD in a study of 941 substance users, and Carroll et al. ${ }^{17}$ reported a similar finding in a study of 298 patients undergoing treatment for cocaine dependence.

In contrast, the lack of any association between age at first use of the other substances and ADHD may indicate that in this population other factors determine age at first use of tobacco, alcohol and cannabis. The results for alcohol and cannabis in the present study agree with those reported by Galéra et al..$^{5}$ in a study of risk factors for substance use among 1,103 youths, where they found that the association between childhood attention problems and substance use is confounded by a range of other factors. However, our findings are different from those reported by Bidwell et al. ${ }^{7}$, who found a lower age at first use of cannabis in patients with ADHD in a study of 376 undergraduates. Dunne et al. ${ }^{16}$ also found differences in the age at first use of tobacco, alcohol and cannabis between groups with and without ADHD. Despite the conflicting results, the present study found an inverse correlation between the frequency of ADHD symptoms and age at first use of all the substances studied. This could indicate that among patients treated in therapeutic communities, those with more frequent $\mathrm{ADHD}$ symptoms may start to use tobacco, alcohol, cannabis and cocaine earlier than patients without any or less frequent symptoms of ADHD. A larger sample or a sample consisting of patients with a higher degree of dependence might produce results similar to those reported in other studies. ${ }^{16,18}$

In the $\mathrm{ADHD}$ patients in therapeutic communities, a lower age at first use of cannabis in patients with ADHD appears to lead to heavier use of cannabis as well as cocaine. These correlations are specific to the ADHD group, once they were not identified in the group without $\mathrm{ADHD}$ or in the overall group. This finding was also reported by Galéra et al., who established a correlation between early exposure to cannabis and use of the substance at an older age. In addition to the pathophysiological mechanism, sociocultural factors associated with early cannabis users may favor heavier use of cocaine and its derivatives ${ }^{5}$. Despite being the drug to which the fewest patients had a history of exposure, cocaine caused the most dependence (substance use disorder) in the patients investigated. Compared with all the other drugs, cocaine created a statistically significantly higher number of dependent users.

Early use of cocaine and its derivatives may be the reason why patients with ADHD in the therapeutic communities had a lower age at admission. Although there was no difference in the percentage of users who became dependent between the populations with and without ADHD, the fact that patients with $\mathrm{ADHD}$ had earlier contact with cocaine makes them more susceptible to dependence at a younger age, which in turn may mean that they are admitted to rehabilitation earlier. Carroll and Rounsaville ${ }^{17}$ also found that patients with $\mathrm{ADHD}$ are admitted for treatment for cocaine dependence earlier but, unlike the present study, also found heavier cocaine use in patients with ADHD.

In the population studied here, there was a high prevalence of $\mathrm{ADHD}$ compared to the general population. In addition, individuals with ADHD were found to have different patterns of drug addiction behavior; such as the age at first use of cocaine, age on admission to rehabilitation, connection between early use of cannabis and severity of cocaine use at later ages. For $\mathrm{ADHD}$ patients in therapeutic communities, 
earlier use of cannabis may have led to heavier use of cannabis and cocaine at a later age. In these patients, regardless of the specific cause, the occurrence of ADHD set a lower age on admission for rehabilitation. This characteristic may be explained by the earlier contact with the drug that caused the most dependence, cocaine. However, ADHD subtypes do not seem to progress to differences in the patterns referred to. In ADHD patients, correlation between the severity of cocaine use and a lower age at first contact with cannabis may justify the monitoring of ADHD youth in order to avoid the contact with cannabis, mainly in social standards similar to those shown by the patients assessed by this study.

\section{References}

1. American Psychiatry Association. Diagnostic and statistical manual of mental disorders. 5th ed. Washington, DC:American Psychiatric Association;2013.

2. Cantwell DP. Attention deficit disorder: a review of the past 10 years. J Am Acad Child Adolesc Psichiatry. 1996;35(8):978-87. doi:10.1097/00004583-199608000-00008

3. Barkley RA. Behavioral inhibition, sustained attention, and executive functions: constructing a unifying theory of ADHD. Psychol Bull. 1997;121(1):65-94. doi:10.1037/0033-2909.121.1.65

4. Russell VA. Overview of animal models of attention deficit hyperactivity disorder (ADHD). Curr Protoc Neurosci. 2011; Chapter 9: Unit9.35. doi:10.1002/0471142301.ns0935s54

5. Galéra C, Pingault JB, Fombonne E, Michel G, Lagarde E, Bouvard MP et al. Attention problems in childhood and adult substance use. J Pediatr. 2013;163(6):1677-83.e1. doi:10.1016/j.jpeds.2013.07.008

6. Tapert SF, Baratta MV, Abrantes AM, Brown SA. Attention dysfunction predicts substance involvement in community youths. J Am Acad Child Adolesc Psychiatry. 2002;41(6):680-6. doi:10.1097/00004583-200206000-00007

7. American Psychiatric Association. Diagnostic and statistic manual of mental disorders. 4th ed. Washington, DC:American Psychiatric Association; 2000.

8. Kessler RC, Adler L, Ames M, Demler O, Faraone S, Hiripi E et al. The World Health Organization Adult ADHD Self-Report Scale (ASRS): a short screening scale for use in the general population. Psychol Med. 2005;35(2):245-56. doi:10.1017/S0033291704002892

9. Mattos P, Segenreich D, Saboya E. [Transcultural adaptation of the Adult Self-Report Scale into portuguese for evaluation of adult attention-deficit/hyperactivity disorder (ADHD)]. Rev Psiquiatr Clin (Santiago). 2006;33(4):188-94. Spanish. doi:10.1590/S0101-60832006000400004

10. WHO ASSIST Working Group. The Alcohol, Smoking and Substance Involvement Screening Test (ASSIST): development, reliability and feasibility. Addiction. 2002;97(9):1183-94. doi:10.1046/j.1360-0443.2002.00185.x

11. Henrique IFS, Micheli D, Lacerda RB, Lacerda LA, Formigoni ML. [Validation of the Brazilian version of Alcohol, Smoking and Substance Involvement Screening Test (ASSIST) [. Rev Assoc Med Bras. 2004;50(2):199-206. Portuguese. doi:10.1590/S0104-42302004000200039

12. Feldman HM, Reiff MI. Clinical practice. Attention deficithyperactivity disorder in children and adolescents. N Engl J Med. 2014;370(9):838-46. doi:10.1056/NEJMcp1307215

13. Ballon N, Brunault P, Cortese S. Sensation seeking and cocaine dependence in adults with reported childhood ADHD. J Atten Disord. 2015;19(4):335-42. doi:10.1177/1087054714543651

14. De Alwis D, Lynskey MT, Reiersen AM, Agrawal A. Attention-deficit/hyperactivity disorder subtypes and substance use and use disorders in NESARC. Addict Behav. 2014;39(8):1278-85. doi:10.1016/j.addbeh.2014.04.003

15. Upadhyaya HP, Carpenter MJ. Is attention deficit hyperactivity disorder (ADHD) symptom severity associated with tobacco use? Am J Addict. 2008;17(3):195-8. doi:10.1080/10550490802021937

16. Dunne EM, Hearn LE, Rose JJ, Latimer WW. ADHD as a risk factor for early onset and heightened adult problem severity of illicit substance use: na accelerated gateway model. Addict Behav. 2014;39(12):1755-8. doi:10.1016/j.addbeh.2014.07.009

17. Carroll KM, Rounsaville BJ. History and significance of childhood attention deficit disorder in treatment-seeking cocaine abusers. Compr Psychiatry. 1993;34(2):75-82. doi:10.1016/0010-440X(93)90050-E

18. Bidwell LC, Henry EA, Willcutt EG, Kinnear MK, Ito TA. Childhood and current ADHD symptom dimensions are associated with more severe cannabis outcomes in college students. Drug Alcohol Depend. 2014;153:88-94. doi:10.1016/j.drugalcdep.2013.11.013 